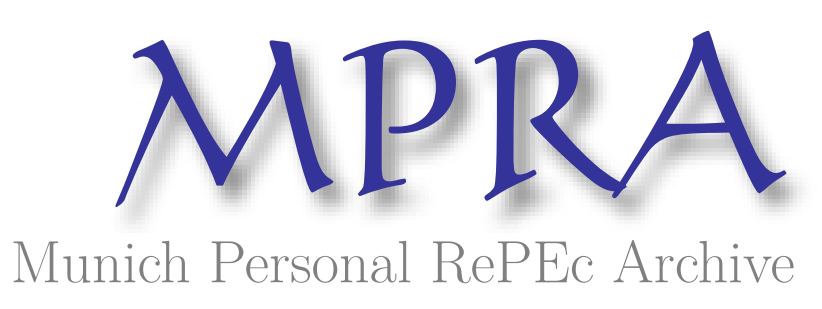

\title{
Sourcing ethics in the textile sector: The case of $\mathrm{CA}$
}

Graafland, J.J.

Tilburg University, CentER

2002

Online at https://mpra.ub.uni-muenchen.de/20769/

MPRA Paper No. 20769, posted 22 Feb 2010 07:34 UTC 


\title{
Sourcing ethics in the textile sector: the case of C\&A
}

\author{
by Johan J. Graafland
}

Paper presented at the $14^{\text {th }}$ annual EBEN conference in Valencia

September 2001

\begin{abstract}
During the last years competition in the textile sector has increased, putting financial returns under considerable pressure. As a result, production has shifted to low wage countries in the third world. This has raised the relevance of ethical procedures. This paper analyses how C\&A as one of the largest Western apparel companies organises its sourcing ethics, notwithstanding the financial pressure in the market. Based on interviews with Asian suppliers of C\&A during the second half of 2000, we review the opinions of external stakeholders about the sourcing ethics of C\&A. Finally, we evaluate C\&A's sourcing ethics from a theoretical perspective.
\end{abstract}

Keywords: business ethics, audits, family business, sourcing ethics, corporate social responsibility

\author{
Tilburg University \\ Room P2211 \\ Warandelaan 2 \\ P.O. Box 90153 \\ 5000 LE Tilburg \\ The Netherlands \\ phone:31 134662702 \\ fax:31 134662892 \\ E-mail:J.J.Graafland@kub.nl
}


Fashion is merchandised from all over the world, especially in Europe, Asia and, to a lesser extent, in Africa. A single item of clothing may be made by a number of production units. The resulting supply chain is complicated and has several stages (see Figure 1). For each stage different countries are optimal as location. For the fabric production and garment assembly, low wage East Asian countries like Sri Lanka, Thailand and Phillippines are suitable. These countries still have the capacities of producing clothes, which has almost disappeared in Western countries. For \begin{tabular}{|l|}
\hline Design, collection definition, samples \\
Product \\
development \\
Cotton production, knitting, bleaching, printing, dyeing \\
Fabric production \\
Fabric cutting and stitching \\
Garment Assembly \\
Merchandising, packaging, transit, distribution, retail \\
nictrihı ıtinn
\end{tabular} prototyping, East European countries are more fit, like Poland, Hungary, Estonia and Bulgaria. Pattern design takes place in South European countries like Turkey, Portugal, Greece and Spain. Collection design is done in West-European countries like Germany, France and Italy.

Increasing competition and a stagnating clothing market have been putting financial returns under considerable pressure. Several Western apparel companies closed stores. For example, Kreymborg closed all its operations in Belgium and the Netherlands. Also C\&A was forced to downsize its operations. The increased competition between clothes retailers has triggered a high concern for low cost strategies. As a result, the location of suppliers moves from relative high wage countries to relative low wage countries in the third world. In the coming years production will shift to countries like China, Indonesia, Bangladesh, Vietnam and India. However, the labour conditions in these relatively poor countries are bad. In the Western countries there is considerable public concern about the conditions under which goods are produced in the developing countries. Sourcing is now a subject of vigorous debate between companies, unions, NGOs and governments. Low prices imply low wages of the employees of the suppliers. Südwind (2000) reports that the average wage per day for female sewers in the textile sector in Indonesia equal $\$ 0,9$. Including overwork, the monthly wage is between $\$ 40$ and $\$ 50$. As a share of the final retail price, the labour costs in production of the clothes only equals $1 \%$ (Robins and Humphrey, 2000), compare with $25 \%$ for brand profit, overheads and promotion. This has raised the relevance of applying sourcing ethics.

In this article we investigate how one of the largest Western textile retail companies, C\&A, organises the implementation of its values in the sourcing process. 
In Europe, C\&A has about 450 stores. About half of the European sales is merchandised in Germany. C\&A is a family company owned by the Brenninkmeijer family. Besides C\&A, the family also owns the fashion stores of Marca in Europe, which are located in Germany, France and the Benelux. C\&A is an interesting case. On the one hand, the ethical standards of C\&A are known as relatively high compared to other Western companies. On the other hand, C\&A's profitability has been extremely low and even negative in the last five years. Especially in the United Kingdom and Germany C\&A was unprofitable during the late nineties (HandelsZeitung). An interesting question is how this has affected the ethical standards of C\&A. ${ }^{1}$

Our research is based on 25 personal in-depth interviews with C\&A managers and 12 personal interviews with Asian suppliers of C\&A during the second half of 2000 , supplemented by articles in newspapers and other publications. Section two describes several aspects of C\&A's sourcing ethics like the Code of Conduct for the Supply of Merchandise of C\&A and the audit organisation SOCAM that controls the application of this code. What are the results of these audits? How does C\&A deal with infringements? The next section describes how external stakeholders like C\&A's suppliers and NGO's view the ethical standards of SOCAM. The last section evaluates C\&A's sourcing policy from a utilitarian point of view and in terms of some procedural norms.

\section{C\&A's sourcing ethics: code of conduct for suppliers and the auditing process}

The mission statement of C\&A states that C\&A has a strong sense of ethical standards and social responsibility. C\&A organises ethics by using codes of conduct. The core values of C\&A with respect to the sourcing process are explained in the Code of Conduct for the Supply of Merchandise (C\&A, 1996). This code was introduced in 1996. The purpose of this code was to translate the ethical commitments of C\&A into action in the workplace. Compliance with the code became a condition of each merchandised order.

The code requires that suppliers respect the ethical standards of C\&A in the context of their particular culture. Suppliers should have fair and honest dealings to all others with whom they do business, including employees, sub-contractors and other third parties. In addition to this general requirement, the code specifies detailed requirements related to employment conditions. For example, the use of child labour is absolutely unacceptable. Workers must not be younger than the legal minimum age and not less than 14 years. Wages must be comparable with local norms and comply with local laws. Furthermore, the code requires that suppliers

\footnotetext{
${ }^{1}$ For an analysis of the relationship between profits and ethics, see Graafland (2001a).
} 
make full disclosure to C\&A of all facts concerning production and the use of sub-contractors. The suppliers are obliged to authorize SOCAM (see below) to make unannounced inspections of the manufacturing facility.

C\&A endorses the social values which underlie the ILO conventions. It is also prepared to listen to suggestions of other parties. For example, in 1998 C\&A incorporated a requirement that workers should be allowed freedom of association as long as these associations are legal in their own country. The formulation is, however, not as strict as in the ILO convention or OECD guidelines (2000), which prescribe a right to be presented by trade unions and collective wage bargaining. $C \& A$ argues that if this requirement is in conflict with local law and established practice, it is unrealistic to try to enforce this. For example, in Bangladesh, suppliers do not cooperate with unions because they are (in the supplier's view) highly politicized and militant and are more interested in their own power than in the labour conditions of workers. According to some suppliers, workers are therefore not interested in unions. In such a case, C\&A will not force the presence of unions.

A number of clothing companies like Otto Versand in Germany have also committed to implement $S A 8000^{2}$ in their supply chain. C\&A does not apply this standard, because SA8000 is defined for the total chain and therefore difficult to implement in the complex supply chain of textiles, in contrast to more concentrated sectors like the auto-industry. According to C\&A, most suppliers cannot meet this standard. ${ }^{3}$ Probably only 15 tot $20 \%$ of them will succeed. Instead of focussing on the examples of best practise in the top $20 \%$ of suppliers, C\&A puts energy in the less spectacular issues of the other $80 \%$ suppliers and follows a practical approach. The purpose is to improve the standards of suppliers step for step in a realistic way. C\&A argues that if you only concentrate on the best practises and stop business with other suppliers, you are also not able to improve the situation of these business.

SOCAM: the audit organisation of C\&A

2 Social Accountability, developed by the American Council on Economic Priorities Accreditation Agency (CEPAA) in cooperation with employers, unions and NGO's.

${ }^{3}$ Besides the norms described in the C\&A code, SA8000 requires no discrimination, living wages sufficient to meet the basic needs of a family, no excessive working times (max 48 hours, overwork only incidental), and verification by an external bureau. A disadvantage of SA8000 is that it is a contract between the suppliers and the audit institute. It makes the suppliers responsible, not the Western apparel companies. Moreover, the subcontracters are also not included. See Handelskrant (2000). 
In order to ensure that the Code of Conduct for the Supply of Merchandise would be much more than simply a paper commitment, C\&A set up in the same year an organisation that would audit compliance with the code and promote the awareness of the code. This organisation is named SOCAM (Service Organisation for Compliance Audit Management). ${ }^{4}$ Before, working standards were enforced by Mondial, C\&A's worldwide sourcing organisation. Although Mondial managers were aware of the importance of social factors and were able to monitor and influence employment practises within production units, this was not their primary task. They were not capable to carry out auditing of compliance, because they had to give advance warning when visiting factories. Unscrupulous factory managers could take advantage by covering up abuses until the visit was over. Furthermore, there was a conflict of interest between Mondial's task to conclude competitive contracts at the one hand and controlling for the labour conditions on the other hand. A final reason is that Mondial captures only part of C\&A merchandise. Hence, there was a need for an independent auditing procedure.

According to the director of SOCAM, SOCAM was set up for four reasons:

- The Brenninkmeijer family attaches specific value to ethical sourcing (the intrinsic value function);

- To be able to answer questions of customers and organisations (the dialogue function);

- A company should know under which conditions its merchandise is produced in order to improve these conditions (the management function);

- To upheld a good reputation, although this should not be the basic reason (the reputation function).

SOCAM is funded by C\&A. The budget is approximately $\$ 3$ million each year. It employs thirteen people. Although SOCAM is funded by C\&A and closely works together with C\&A's Sourcing Department, it is independent of C\&A's commercial activities. The director of SOCAM has firsthand knowledge of supplier operations throughout Europe, the Far East and Africa. SOCAM has full authority to monitor the standards which are defined by the code. The director of SOCAM is only accountable to the board of C\&A. The only task of SOCAM is auditing. The decision what to do when unacceptable working conditions are detected is up to C\&A Buying, although the SOCAM director can make suggestions how to proceed.

\section{The audit procedures}

Each year, the director of SOCAM makes a plan for the locations to be visited.

${ }^{4}$ See the annual report of SOCAM $(1998,1999,2000)$ or look at the internet-address www.socam.org. 
Countries with dubious reputations are visited more frequently than countries with a good reputation. For example, in a country like Italy with 159 suppliers (and 499 production units) the probability of serious infringements is smaller than in Turkey or Pakistan. SOCAM demands information about the location of all production units where C\&A merchandise is made and makes unannounced visits to audit their working practises. When visiting a production unit, SOCAM auditors present their SOCAM ID-cards at the factory gate and expect free access to the areas of production (which is a condition of the C\&A merchandise order). In $80 \%$ of the cases, the auditors receive entrance without any problems. In $10 \%$ of the cases, some talks are required, whereas in the other $10 \%$ the entrance is refused or the cooperation is minimal. SOCAM auditors try to see the factory first in order to secure a 'reality-check'. Often, three minutes are enough to get an overall idea of the state of the production unit. Subsequently, all kinds of details are investigated. For this purpose, SOCAM auditors use a list of criteria to assess the factory against its performance, which contains aspects like the use of child labour, forced labour, abuse of home workers, safety hazards (like obstructed emergency exits), infringement of environmental standards or unhygienic working conditions.

In case of non-compliance with the code, SOCAM always tries to encourage suppliers to improve conditions through talking to the management. Talks to employees should be done with care, because workers who speak to auditors can be victimised or dismissed. It is in no-one's interests if contracts are ended without giving suppliers an opportunity to improve matters. SOCAM can make recommendations to the C\&A's Sourcing Department, which may include suggestions like sending a warning letter, cancellation of orders or suspension of business for a certain period of time. During this period the supplier has the opportunity to develop a corrective plan during a period of suspension. The content of the corrective plan is up to the producer. C\&A requires, however, that the plan may not harm the people of the production unit. For example, in case of child labour, the corrective plans should include alternative arrangements for these children. They may not be simply dismissed. Five years ago, C\&A would have stopped business if child labour would have been detected. However, now it recognizes that you should be realistic about what is attainable in the context of the local conditions. If the corrective plan is acceptable, this may lead to a resumption of business with C\&A. SOCAM controls the realisation of the plan by unannounced visits. If the corrective plan is without desired results, C\&A ends the contract altogether.

All information obtained by SOCAM is treated as confidential in order to build a relationship of trust with the manufacturers. SOCAM considers this to be a necessary condition for an effective operation of the code which outweighs the advantages otherwise conferred by complete transparency.

The difficulty of auditing the full supply chain is illustrated by the following 
problems. Sometimes suppliers fail to disclose all the production units that are used or give an incorrect address of the production unit. For example, in November 1998 SOCAM auditors attempted to visit a production unit of a sub-contractor in Vietnam, but the address given was found to be residential. The registration of the (constantly changing) list of addresses of the production units used by the (almost 1300) suppliers of C\&A is a major task. Alternatively, suppliers fail to inform production units of SOCAM's role and, as a consequence, the production units refuse SOCAM entrance to the factory. Also in the case of homework, the auditing process becomes very difficult. Extending the auditing to this group presents major logistical problems for SOCAM.

\section{Results of SOCAM}

In the 1999 report SOCAM lists (among others) the following results:

- $\quad$ unannounced visits to 1459 production units in 1999 (and 4969 since 1996);

- $\quad 800$ letters were sent to suppliers asking their production units to improve in areas where infringements were found; in 226 cases there were major infringements (against 117 in 1998 and 91 in 1997).

- $\quad$ C\&A stopped doing business with 49 suppliers (and 141 since 1996). Twenty-eight of them (58 since 1996) were subsequently reinstated following acceptance of a corrective plan.

These results give rise to two notions. Almost two thirds of all visited production units show shortcomings, whereas $15 \%$ exhibit major infringements. On the one hand, this illustrates the importance of SOCAM. On the other hand, it also illustrates the low ethical standing of part of the textile business.

In the early years of SOCAM the main cause of termination of business has been either evidence of the use of child labour or intolerable working conditions. Child labour is a non-negotiable aspect of the C\&A code. In cases of doubt, birth certificates or other proofs of age are requested. As birth certificates can be easily falsified, sometimes a doctor is consulted to estimate the age. In the last two years, child labour is rarely detected anymore. Indeed, as more Western clothing companies insist on the non-use of child labour, child labour diminishes in the export industries and, probably, shifts to factories producing for the home-market in the developing countries.

Because of this trend, the provision of acceptable working conditions for all employees is more significant. The number of infringements in these areas is rising, partly because of improvements in the auditing procedure. SOCAM inspects not only arrangements on the factory floor - machine safety, hazardous chemicals, fire exits but also other aspects of the infrastructure like cooking and canteen arrangements, lavatories, washing facilities and dormitories. Production units do not rate as 
unacceptable if only one of these aspects is insufficient. Only if a production unit fails on several of these other criteria it will be rated as unacceptable.

\section{Opinions of external stakeholders about C\&A's sourcing ethics}

In this section we review the opinions of two important groups of external stakeholders: the suppliers of C\&A and the NGO's in the textile sector.

\section{C\&A’s suppliers}

During January 2001, I visited Asia and spoke with twelve suppliers in various countries (Thailand (Bangkok), Bangladesh (Dhaka) and India (Tirupur)) and asked their opinion about SOCAM. The larger Asian suppliers have often inspections from auditors of their customers. Most suppliers state that, from an ethical perspective, C\&A is always one step before other Western apparel companies. Competitors are coming closer but are not as good as C\&A. For example, GAP and LEVI have their own audit organisations. NIKE uses external audits. Most use local offices of, for example, Price Waterhouse Coopers. H\&M has also developed a code of conduct, but it has no audit organisation. Compared to other audit organisations, SOCAM does more frequent visits, has more experience and more understanding of the local situation. Another advantage of SOCAM is that it operates in different Asian countries.

Several suppliers think that the audit activities improve the working conditions and raise the awareness of the relevance of it. One supplier in Dhaka gave as an example that fire exit routes were made after a suggestion of SOCAM. Suppliers become more known with the needs of their European customers. One supplier noted that he would keep the standards even if SOCAM would stop its audits, because the workers are now used to it. Moreover, other retail companies demand it too. Finally, in some cases the requirements of SOCAM also raise the productivity. For example, if the sanitary is good, workers will not leave to other firms.

One supplier in India stated that, although he respected SOCAM, Mondial does most of the effort to raise the labour standards of suppliers. Another supplier in India also argued that SOCAM is super-abundant, because Mondial already inspects the labour conditions of the suppliers. C\&A is always one step before
Competitors
\$OCAM audits improve the labour
onditions
\$OCAM is super-abundant, because
Mondial already inspects the labour
donditions
SOCAM causes unfair competition Indeed, Mondial puts a continuous effort 
in raising the working standards of the suppliers. Mondial looks for suitable suppliers and presents them to the buyers of C\&A. Mondial Bangladesh, for example, works with a selected group of 20-25 suppliers. In contrast to SOCAM, Mondial looks into all production units and inspects the production process almost every day. Mondial uses its own compliance audit form, including aspects like awareness of SOCAM by factory staff ${ }^{5}$, environment, availability of age proof records, cleanliness, lighting, ventilation, fans, emergency exit, fire extinguishers, first aid box, canteen, drinking water facilities, and the presence of toilets. A supplier must accord with these requirements or take action to do so before being accepted as a supplier.

Several suppliers complained that SOCAM causes unfair competition, because production units selling to C\&A buyers via other European importers are not controlled as well as the suppliers of Mondial. According to these suppliers, SOCAM has no opportunity to visit all production units of importers, because they do not disclose all the subcontractors. Indeed, both in Asia and East Europe importers can evade inspections of the production units from which they buy. Therefore, according to these suppliers, C\&A is implicitly using two standards, a high standard for suppliers contacted by Mondial and a low standard for the suppliers of importers.

In response to this criticism of suppliers, C\&A argues that SOCAM has only one standard and applies this standard to all suppliers. SOCAM is aware that the transparency in the direct network is higher than in the indirect network and that, as a result, the indirect network is less under control. Although it cannot guarantee that suppliers submit all names and addresses of their production units, SOCAM does have names and addresses of production units of all indirect suppliers and there is no exception or preference made in the selection. Moreover, the percentage of production units which have been audited is higher for indirect suppliers than for direct suppliers. In particular, for European suppliers $81 \%$ of all audits concerns production units of indirect suppliers. For Asian suppliers this is $50 \%$.

Some managers of C\&A want to improve this situation by promoting direct sourcing. However, C\&A buyers are free to chose between direct sourcing and indirect sourcing. At the moment, the growth targets for direct sourcing are not realised.

Non-gouvernemental organisations in the textile sector

C\&A had several discussions with NGOs in the past about the working conditions of firms that supply clothes to C\&A. There can be several causes for different opinions between NGOs and C\&A. Sometimes the information of NGO's is different from the

\footnotetext{
${ }^{5}$ In the case of one factory in Dhaka which I visited, the factory staff was not known with SOCAM.
} 
information of $C \& A$, for example, because of differences in investigation procedures. NGOs often operate through undercover interviews of employees of a production unit. This is not allowed to C\&A. The contracts with the suppliers require a formal procedure. Another source for different opinions is a difference in ambition between what C\&A wants (as described in its code of conduct) and what NGO's ask for.

An example of different information is a complaint of the German research institute Südwind that came up with miserable working conditions for women in two Indonesian factories, Kolon Langgeng and Kahoindah Citragarment, who supply clothes to C\&A. (Südwind, 2000). Women would have been beaten and sexually abused. In case of pregnancy they would lose their job. In these factories, labels of C\&A were present. C\&A denied, however, recent contacts with these factories. With Kolon Langgeng the latest contacts were in 1995, with Kahoindah Citragarment in 1998. The presence of C\&A labels was explained by the fact that local companies sometimes save labels of $C \& A$ for more than ten years and use them to prove to other retailers that they have produced for large companies.

An example of different ambitions is the complaint of intolerable working conditions in factories delivering to C\&A given in Musiolek (1999) by Amirul Haque Amin. Amin mentions an example of a factory in Bangladesh with 600 employees, who normally work from 8 o'clock A.M. to 8 o'clock P.M. and often to 10 o'clock P.M. There is no right on one resting day in a week. The working week varies between 70 and 80 hours. However, the C\&A code does not cover working times. Otherwise, Amin also found that this factory infringe many other conditions which are mentioned in the C\&A code. For example, wages were below the official minimum wage, a fire extinguisher and first aid box were not available and employees were not trained in safety aspects. Furthermore, participation to union activities were forbidden and punished by dismissal. A Bengalis translation of the C\&A code was also not present.

Also the lack of a guaranteed living wage in the C\&A code sometimes causes discussions with NGOs. If a sewing-woman only receives 1 per cent of the final selling price of a garment, this sounds very unethical to a Western customer. However, C\&A argues that the Western criteria for fair payment do not apply to non-Western countries. Of course, people should at least receive legal minimum wage. But raising the wage beyond the competitive level paid by other firms would result in a competitive disadvantage. The code of C\&A does not guarantee a living wage. If the legal minimum wage in a country is insufficient for a living wage, the possibilities of C\&A to force a producer to change its wage level is limited. Ending trade relationships on this ground does not solve the problems, according to C\&A.

Differences in ambition also sometimes show up if local NGOs use Western NGOs to internationalise small local conflicts and impact the local producer through pressure on the Western buyer. For example, recently a NGO from Cambodia had a 
conflict with the supplier about the number of chicken mixed into the rice of the workers. According to $C \& A$, this kind of conflicts should be resolved at the local level. Only if human rights are violated, C\&A feels responsibility for intervention in conflicts.

Another point of discussion with NGOs is the independence of SOCAM. In particular, one of the main protagonists of the ethical debate on production standards in Europe, the Clean Clothes Campaign (an alliance of several different NGOs, unions and religious communities active in many countries) pleas for an independent monitoring.. They agree that SOCAM is a positive step, but mainly address it as a PR exercise as long as there is no independent control. Also Amnesty International is critical about the independence of SOCAM.

Sometimes, C\&A cooperates with NGOs and welcomes the information offered by NGOs. For example, recently SOCAM was alerted by a UK based NGO that an Indonesian supplier ignored the right of workers to form a union. SOCAM sent an auditor, but by the time that he arrived, the problem had been resolved. Another example is the cooperation between C\&A Germany with Terre des Hommes. One particular project is a vocational training centre in Tirupur in India. This project attempts to combine the great experience of a NGO specialized in the prohibition of child labour and its contacts with local NGOs with the supplier connections of C\&A as one of the main retailers with global sourcing.

Despite their critical attitude, NGO's evaluate the efforts of C\&A in a positive way compared to other European retailers. In ELAN (1999), C\&A is mentioned as one of the two Dutch companies (besides Shell) which publish an ethical annual report and controls the figures by audit organisations. ${ }^{6}$ Also more critical NGOs like the Clean Cloth Campaign (CCC) argue that C\&A does at least something. People of CCC in the Netherlands believe that C\&A contributes more to social responsibility in the clothing sector than other Dutch firms like de Bijenkorf, de HEMA, Hunkemöller and V\&D (Handelskrant, 2000). The relative high standards of C\&A are also confirmed by the International Institute for Environment and Development (Robins and Humphrey, 2000), who compares C\&A with some other companies operating on the British market, like M\&S, Next, BHS and Littlewoods. C\&A was the first company that introduced a code of conduct and the only company that monitors the compliance to the code. Furthermore, C\&A is the only high-street fashion retailer that has adopted the Oeko-Tex 100 standard, ranging from $33 \%$ for trousers and skirts to $77 \%$ for jeans and $98 \%$ for socks. C\&A is also the only company that certificated for the ISO14001 standard. In 1998, C\&A was certificated in all European countries.

\footnotetext{
${ }^{6}$ In contrast to C\&A, Shell uses external verification by KPMG and PricewaterhouseCoopers on a selected number of ecological and social aspects. See the Shell Report (1999).
} 


\section{Evaluating C\&A's sourcing ethics}

In the previous sections we have looked at the opinions of suppliers and NGOs on several aspects of C\&A' sourcing ethics. In this section we evaluate C\&A's sourcing ethics from a more theoretical point of view. First, we characterize the sourcing ethics in terms of three strategies: compliance, integrity or dialogue strategy. Second, we evaluate C\&A's sourcing ethics by application of substantial ethical principles. In particular, we consider the usefulness of SOCAM from a utilitarian perspective. Third, we give an overall evaluation of C\&A' sourcing policies in terms of purely procedural ethical standards.

\section{Characterizing C\&A's ethical strategy}

There are several ways of defining and organising ethical behaviour. Hummels and Karssing (2000) distinguish three types of strategies. In the first strategy - the compliance strategy - the company develops concrete standards of behaviour which are communicated to all members of the organisation. The ethical quality of the organisation is guaranteed by the supervision and control of the managers and employees or other business partners. Those who are found shirking are punished.

The second strategy - the integrity strategy - does not rely on the compliance of strict rules, but rather on the own responsibility and integrity of the individual employees on basis of internalized values. Integrity means that managers and employees are prepared to fulfil their tasks in a professional, accurate and responsible way, taking into account all relevant interests. In order to apply this strategy in a successful way, the company must define clear core values and train managers and employees to apply these core values in concrete situations.

The third strategy - the dialogue strategy - pays attention to the expectations of the stakeholders of the company. This strategy focusses on the responsiveness to the ideas, interests and values of others. The organisation constantly tries to learn from new situations and from what external parties communicate.

Although C\&A uses a mixture of these strategies, the main focus is on the compliance strategy. For example, the C\&A code mainly contains rather concrete rules that can be checked and clearly outline what must be done or not done. The code is communicated to all suppliers and audited by SOCAM. Infringements are reported by SOCAM to C\&A Buying and sanctioned by suspending business. However, C\&A is also aware that, from a broader perspective, a strict compliance strategy can sometime produce adverse results. Therefore, sometimes C\&A uses a flexible approach by, for example, looking for alternatives from which employees of suppliers really benefit. Furthermore, C\&A also uses the dialogue strategy by 
allowing suppliers to develop corrective plans and incidentally by cooperating with NGO's.

\section{Evaluating SOCAM from a utilitarian perspective}

In 2000 all C\&A divisions and activities were evaluated by the European board of $C \& A$. In order to raise the cost effectiveness and restore the profitability of the C\&A business, the board looked for opportunities to cut costs by eliminating unprofitable activities. Also SOCAM was reviewed in this process. After a presentation of the director of SOCAM, the board decided to continue the audit activities by SOCAM. How should we evaluate this decision of the board from an ethical point of view? In particular we are interested in the following question: does C\&A have a moral obligation to continue SOCAM activities?

In order to answer this question, we only review this question from a utilitarian perspective. ${ }^{7}$ Although there are several difficulties with utilitarianism (Beauchamp, 1991; Chryssides and Kaler, 1993; Velasquez, 1998), this theory has some profound advantages. For one thing, it fits with the way many people make up their mind, namely by looking at the beneficial and harmful consequences of a particular action. It also fits with the value of efficiency. With respect to the problem of measurement, the strong assumptions of utilitarianism can be relaxed when such measurements are impossible. Utilitarianism merely requires a systematic overview of the benefits and costs. With respect to the problems with rights and justice, it can be argued that in case of conflicting rights, utilitarianism can play a useful role by weighting the interests involved. Indeed, an adequate formulation of rights can make substantial use of consequential reasoning of the type standardly used by utilitarianism (Sen, 1987).

Box 3 gives an overview of the consequences of SOCAM for various stakeholders. First, my talks with Asian suppliers indicate that they appreciate the audits of SOCAM, provided that all competitors are also subjected to SOCAM audits. Since this is not the case, some suppliers have mixed feelings about SOCAM as raising the labour conditions in line with C\&A's code increases their production costs. However, other suppliers argue that stopping SOCAM will not really change their labour conditions and in some cases the requirements of SOCAM also raise the productivity.

${ }^{7}$ For the application of other ethical theories on this question, like the deontological theories of Kant, Locke, Nozick and Rawls, the virtue theory of Aristoteles (Desjardin, 1984; Maclntyre, 1985), and some specific business ethical theories like the shareholder of Friedman (1970), stakeholder and the integrated social contract theory of Donaldson and Dunfee (1999), see Graafland (2001b). 
From the perspective of the employees of suppliers and their local communities, the SOCAM audits are unambiguously positive, because they stimulate employers to improve the labour conditions of workers. Since SOCAM follows a practical approach and relates its standards to the overall level of welfare in the community to which the supplier belongs, the competitive disadvantages caused by the SOCAM requirements, if any, will be relatively small. Moreover, SOCAM takes care that it does not harm the interests of individual employees. Therefore, the probability that some individual employees will suffer from these audits is relatively small.

Next, let us consider the interests of the Brenninkmeijer family. Apart from an intrinsic interest of the family in the ethical standards of the C\&A merchandise (see above), the contribution of SOCAM to C\&A's profits is probably positive. ${ }^{8}$ Indeed, as SOCAM is efficiently organised and only requires a relatively small budget (see above), the benefits from SOCAM in terms of building up a good reputation are likely to dominate its direct costs by diminishing the probability of incidents like the discovery of the use of child labour by suppliers for the production of C\&A merchandise. Publication of such incidents in the media, like in the Mail on Sunday (8 january 1995), has a lasting impact on the public's memory. However, it remains uncertain how this reputation affects the actual shopping behaviour of customers. Experiments of C\&A with products produced in a more ethical way were not successful (see below), which indicates that customers are not prepared to pay for the ethical quality of the clothes. Moreover, it should be noted that SOCAM also generates indirect costs because it limits the possibilities for C\&A buyers to buy from cheap but unethically operating suppliers. Finally, although SOCAM contributes to the ethical standards demanded by the society, it also generates additional (negative) attention of critical NGO's. A strategy of corporate social responsibility therefore creates some risks (KPMG, 1999). However, this consideration is especially relevant when considering a rise in the ethical standards (like in 1996), but is less relevant when considering a reduction in the ethical standards. Therefore, if C\&A would stop SOCAM, the competitive position is more likely to diminish in the longer run, in particular because C\&A's competitors are also investing in ethical standards by now.

${ }^{8}$ For a mathematical economic model of the relationship between profits and ethics, see Graafland (2001c). 
The impact of SOCAM on C\&A's managers and employees is ambiguous. On the one hand, it restricts C\&A buyers in their search for cheap opportunities, since they are obliged to communicate the names and addresses of the suppliers to SOCAM (Trouw, 1999). On the other hand, many C\&A managers are also proud of SOCAM. Finally, C\&A managers and employees also have an interest in the continuity of C\&A as a profitable firm, because their wages, employment perspectives and job satisfaction depend on the profitability of $C \& A$. The net impact of SOCAM on the profitability of C\&A therefore not only affects the interests of the family, but also those of the managers and employees.

We have already noted that the interest of C\&A customers in the ethical quality of the production process is probably positive as long as the costs are relatively small. Many of them will be indignant when the media reports incidents about child labour or other violations of the employee's rights. However, it is uncertain whether they really experience a loss in welfare when they realise that their clothes may be made in deplorable labour conditions. A test on the seriousness of their ethical discomfort is how much they are prepared to pay for a quality standard that secures that their clothes are produced in a responsible way. According to a European Survey of Consumers' attitudes towards corporate social responsibility by Mori (2000) $70 \%$ of European consumers say that a company's commitment to social responsibility is important when buying a product or service and $44 \%$ would be willing to pay more for products that are socially and environmentally responsible. These figures seem implausibly high if compared, for example, with the low market shares of products that are well known for their high ethical standard, like Max Haverlaar coffee. Rather, it seems that these outcomes reflect 'correct answers' that are upward biassed and will not materialize in the actual shopping behaviour of consumers. This is even more true for the textile sector as a whole and the relatively cheap market segment which C\&A covers.

Continuation of SOCAM makes it easier for C\&A's competitors to apply similar ethical standards. Indeed, some other Western apparel concerns who used to apply low ethical standards, have recently also become more interested in these activities.

Also from the perspective of the European governments and the European society as a whole the continuation of SOCAM is positive. The government seeks ways to improve the social and environmental effects of business operations by voluntary measures of business. The OECD guidelines (2000) encourage enterprises to apply high ethical standards in order to realise social and ecological sustainability. SOCAM presents an example of good practises that may stimulate other companies (SER, 2001). However, even from the perspective of the European society as a whole the welfare effects of SOCAM are ambiguous. Whereas the effect on the two P's (planet and people) are positive, the impact on the third P 
(profits) is uncertain (see above). If C\&A fails to become profitable again and the family decides to stop C\&A business, and if (which I doubt) the net impact of SOCAM on C\&A's profits is negative, the continuation of SOCAM would contribute to the loss of jobs by C\&A employees, who will become dependent on social benefits paid by the other European citizens.

Concluding, although it is not possible to give an exact estimate of the welfare effects of SOCAM, my impression is that the net welfare effect of SOCAM is positive. According to the utilitarianism, the positive welfare effect of SOCAM implies that $C \& A$ has a moral obligation to continue these audit activities. The decision of the C\&A board to continue SOCAM can therefore be qualified as an example of corporate social responsibility.

\section{Evaluation: procedural standards}

In order to evaluate C\&A's sourcing ethics from a procedural perspective, we use several corporate virtues or qualities. Corporate virtues are the factors embedded in the corporate structure that encourage ethical behaviour. Kaptein (1998) identifies seven corporate virtues. For our evaluation, we apply these norms to the relationship between C\&A and its suppliers. This gives the following norms: clarity (how accurate and clear are the corporation's expectations towards the moral conduct of the suppliers), consistency (are the ethical standards coherently applied by C\&A), achievability (are the ethical requirements feasible for the suppliers), supportability (does C\&A support suppliers to meet the ethical standards), transparency (how clear does C\&A communicate its social and environmental results), stakeholder participation (how much opportunity do suppliers have to impact C\&A's policy) and sanctionability (are suppliers sanctioned if they deliberately infringe the ethical standards). To these corporate virtues we add five principles of quality for social and ethical accounting, auditing and reporting. From the eight norms developed by Zadek Prudan and Evans (1997), we apply the following five norms: ${ }^{9}$ comparability (are the results of the audits comparable with the results of previous years), evolution (how regular are the audits), management policies and systems (how are ethical standards integrated in the organisation of C\&A), disclosure, external verification and continuous improvement.

Box 4 gives an impression of the procedural ethical standards of C\&A's sourcing. On the whole, C\&A shows a good performance by having a concrete and realistic code of conduct for suppliers, controlling the application of this code by SOCAM, publishing an annual report of the results of SOCAM, sanctioning suppliers

${ }^{9}$ The other three norms, completeness, inclusiveness and disclosure, are already captured by the transparency and stakeholder participation norms of Kaptein (1998). 
who do not meet the requirements of the code and improving the situation by allowing suppliers to develop corrective plans. Mondial supports the suppliers in raising the working standards before presenting them to the buyers of C\&A, whereas SOCAM instructs the management of production units if infringements are detected. Stakeholder participation is encouraged by letting suppliers come up with their own plan for improvements. Furthermore, in order to promote the relationship with suppliers, C\&A recently organised two conferences with suppliers in Italy and Thailand. These conferences aim at a dialogue between C\&A and the suppliers, enables $C \& A$ to explain its vision and provides $C \& A$ with information

about the suppliers' view on C\&A. Incidentally, C\&A has also cooperated with NGOs and made some (unsuccessful) efforts for cooperation with competitors to improve environmental aspects.

Box 4 Evaluation of C\&A's sourcing ethics from a procedural perspective

\begin{tabular}{|l|l|}
\hline norm & application to C\&A's sourcing policy. \\
\hline clarity & rules in the code of conduct are concrete \\
\hline consistency & SOCAM uses one standard; however, indirect sourcing is dominant \\
\hline achievability & rules in the code of conduct are realistic \\
\hline supportability & Mondial assists suppliers; talks of SOCAM with management; \\
\hline transparency & $\begin{array}{l}\text { C\&A uses code of conduct, audits the code by SOCAM and publishes an } \\
\text { annual report of the results }\end{array}$ \\
\hline stakeholder participation & corrective plans by suppliers; supplier conferences; contacts with NGOs \\
\hline sanctionability & $\begin{array}{l}\text { suspension in case of infringements; resumption of business if corrective } \\
\text { plan is acceptable; otherwise termination of business relationship }\end{array}$ \\
\hline comparability & use of fixed checklist in different periods \\
\hline evolution & 1500 unannounced visits to production units each year \\
\hline $\begin{array}{l}\text { management policies and } \\
\text { systems }\end{array}$ & $\begin{array}{l}\text { SOCAM has well organised data-base; SOCAM advises C\&A Buying; } \\
\text { OEKO-tex standard; ISO14001 certification }\end{array}$ \\
\hline externally verified & SOCAM is semi-independent \\
\hline continuous improvement & SOCAM extends check list \\
\hline
\end{tabular}

The audits are made comparable by using a fixed lists of criteria and qualifications. The continuity is assured by the high annual number of unannounced visits by SOCAM. The organisational infrastructure is also relatively good. SOCAM has a well organised data base of the suppliers of C\&A, which allows a rapid response to questions. Furthermore, SOCAM can advise C\&A Buying how to improve the labour conditions of the suppliers. Other aspects of the organisational infrastructure are the 
use of the OEKO-tex standard for babywear and the management system created for the ISO14001 certification. SOCAM also seeks continuous improvement of their procedures. For example, recently SOCAM planned to intensify the audit process by raising the number of questions from 40 to 300 . Other improvements are the construction of a manual of legal regulations per country, the development of environmental criteria. Another goal is to acquire a certification of the auditing process. For this purpose, SOCAM has contracted a consultant of Ernst and Young. ${ }^{10}$

Only with respect to the consistency and the independence of the audits the qualification of C\&A's sourcing policy is mixed. Although C\&A uses one standard, the consistency of the application of the ethical standards is lowered because most of C\&A's merchandise is sourced indirectly via other European importers that cannot be controlled as well as the suppliers of Mondial. Notwithstanding C\&A's intention to increase its involvement in the supply chain, the share of direct sourcing is not rising as much as was planned.

Furthermore, although SOCAM operates independently from C\&A Buying and Mondial, complete independency is not assured. Indeed, complete independency can only be ensured if the auditing process is done by a third-party. This possibly lowers the transparency and reliability. However, the semi-independency of SOCAM also creates benefits. First, an in-house organisation has the advantage that its procedures can be based on a deep understanding of C\&A's sourcing system. The SOCAM staff has proven experience of clothing production and an understanding of the national and cultural contexts in which production units operate, which is vital to the success of the audit. Second, because of their long employment in C\&A, the integrity of the SOCAM researchers is relatively high. As a result, the probability that the research is undermined by bribes is relatively small. If independent audit organisations would have to control the huge number of suppliers of C\&A, they probably have to hire local personnel that is not necessarily more reliable. Third, since all information obtained by SOCAM is treated as confidential, they are more able to build a relationship of trust with the manufacturers. Therefore, suppliers may have a more open attitude which creates opportunities for improving the situation. Fourth, an in-house organisation may be cheaper for C\&A than hiring independent auditors from well known agencies like KPMG or Price Waterhouse Coopers. This enables C\&A to audit a high number of sites. C\&A argues that the merits of SOCAM is also illustrated by the remedial actions taken and genuine improvements in working conditions. How we value these advantages depends on the purpose of the audits. If the gathering of reliable information to convince indirect stakeholders like

${ }^{10}$ In the meantime, SOCAM has obtained the certificate. 
NGOs and the government is the main purpose, full independency may be preferable. If the purpose is to involve direct stakeholders and to improve the management of suppliers, the semi-independency may be more effective.

A third point of concern is that C\&A recently halted the efforts for ISO14001 certification in several European countries. Although in some cases these environmental efforts actually safe money, in most cases there are some additional costs involved. Because of the high administrative burden and due to the current economic problems, C\&A recently stopped its efforts to maintain its certification in some countries. The management system is officially still in place, but without certificate. The reason for putting accreditation on hold was mainly due to the internal pressure caused by an increased workload. This forced the management to reconsider its priorities. As the internal and external audits required for ISO certification were putting too much additional pressure on the C\&A staff, the actions have been reduced to a minimum. In some countries like Belgium C\&A still continues its ISO14001 efforts in order to recertificate in the next round.

This last point illustrates that the increasing competition in the clothing market tends to reduce C\&A's corporate social responsibility efforts. Still, as shown by the positive decision of the European board of C\&A to continue the activities of SOCAM and the efforts of this organisation to improve the audit procedures, the difficult market situation has not completely taken away C\&A's relatively high commitment to corporate social responsibility.

\section{References}

Beauchamp, T.L., 1991, Philosophical Ethics. An introduction to moral philosophy. Tweede editie, Mc.Graw-Hill, Inc., New York.

C\&A, 1999, Mission Statement

C\&A, 1996, The C\&A Code of Conduct for the Supply of Merchandise

Chryssides, G. and J.H. Kaler, 1993, An introduction to business ethics, Chapman \& Hall

Desjardins, J.R., 1984, Virtues and business ethics, in: M. Hoffman (ed.), Corporate Governance and Institutionalized Ethics, Lexington, D.C. Heath \& Co. ELAN, 1999, January, pp. 49-51

Donaldson, T. and T.W. Dunfee, 1999, Ties that bind, Harvard Business School Press.

ELAN, 1999, January, pp. 49-51

Friedman, Milton, 1970, The social responsibility of business is to increase its profits,

The New York Times Magazine, 13 september.

Graafland, Johan J., 2001a, Profits and principles: four perspectives, Journal of Business Ethics, forthcoming

Graafland, Johan J., 2001b, Maatschappelijk ondernemen: analyse, verantwoording 
en fundering, Oration, Tilburg University

Graafland, Johan J., 2001c, Modelling the trade-off between profits and principles, De Economist, forthcoming

Handelskrant, 2000, Beweging in de kleding, pp. 3-6, January

HandelsZeitung, 2000, C\&A zieht nicht mehr alle an, 18-10-00

Hummels, H. and E. Karssing, 2000, Ethiek organiseren, in: R. Jeurissen (ed.), Bedriffsethiek een goede zaak, Van Gorcum, Assen, pp. 196-224

Kaptein, M., 1998, Ethics Management: Auditing and developing the ethics content of organisations, Kluwer Academic Publishers, Dordrecht

KPMG Ethics and Integrity Consulting, 1999, Sustainability Management: balancing and integrating economic, social and environmental responsibilities, Amsterdam

Mail on Sunday, 1995, 8-1-1995

Maclntyre, Alasdair,1985, After virtue. A study in moral theory, Duckworth

MORI, 2000, Research for CSR Europe

Musiolek, B., 1999, Gezähmte Modemultis. Verhaltenskodizes: ein Modell zur Durchsetzung von Arbeitsrechten? Eine kritische Bilanz, Brandes \& Apsel/Südwind

OECD, 2000, The OECD Guidelines for Multinational Enterprises: draft text and commentary

Robins, Nick and Liz Humphrey, 2000, Sustaining the rag trade, International Institute for Environment and Development

Sen, Amartya, 1987, On ethics and economics, Basil Blackwell, Oxford

SER, 2001, Corporate Social Responsibility. A Dutch approach, Royal Van Gorcum, Assen

Shell, 1999, People, planet \& profits; an act of commitment, Shell International, Londen

SOCAM, 1998, Annual Report

SOCAM, 1999, Annual Report

SOCAM, 2000, Annual Report

Südwind, 2000, Das Kreuz mit dem Faden, Texte 11

Trouw, 1999, C\&A speelt een 'open kaart', door Kees de Vré, 19-2-99

Velasques, M.G., 1998, Business ethics. Concepts and cases, Fourth edition, Prentice Hall

Zadek, S., P. Prudan and R. Evans, 1997, Building Corporate Accountability, Eartscan Publications, London 